\title{
Angiotensin-converting enzyme 2: a functional receptor for SARS coronavirus
}

\author{
J. H. Kuhn ${ }^{a}$, W. Li ${ }^{a}$, H. Choe ${ }^{b}$ and M. Farzan ${ }^{c, *}$ \\ a Partners AIDS Research Center, Brigham and Women's Hospital, Department of Medicine (Microbiology and Mol- \\ ecular Genetics), Harvard Medical School, Cambridge, Massachusetts 02139 (USA) and Department of Biology, \\ Chemistry, Pharmacy, Freie Universität Berlin, 14195 Berlin (Germany) \\ b Perlmutter Laboratory, Pulmonary Division, Children's Hospital, Department of Pediatrics, Harvard Medical School, \\ Boston, Massachusetts 02115 (USA) \\ c Partners AIDS Research Center, 65 Landsdowne Street, Brigham and Women's Hospital, Department of Medicine \\ (Microbiology and Molecular Genetics), Harvard Medical School, Cambridge, Massachusetts 02139 (USA), \\ Fax:+1 617768 8738, e-mail: farzan@mbcrr.harvard.edu.
}

\begin{abstract}
Cellular entry of enveloped viruses is often dependent on attachment proteins expressed on the host cell surface. Viral envelope proteins bind these receptors, and, in an incompletely understood process, facilitate fusion of the cellular and viral membranes so as to introduce the viral core into the cytoplasm. Only a small fraction of viral receptors have been identified so far. Recently, a novel coronavirus was identified as the etiological agent of severe acute respiratory syndrome (SARS). The fusion pro-
\end{abstract}

tein gene of SARS coronavirus (SARS-CoV) was cloned and characterized, and shortly thereafter, angiotensinconverting enzyme 2 (ACE2) was shown to be its functional receptor. Identification of ACE2 as a receptor for SARS-CoV will likely contribute to the development of antivirals and vaccines. It may also contribute to the development of additional animal models for studying SARS pathogenesis, and could help identify the animal reservoir of SARS-CoV.

Key words. Severe acute respiratory syndrome; SARS; coronavirus; angiotensin-converting enzyme 2; ACE2; viral fusion.

\section{Introduction}

The susceptibility of cells to viral infection is determined by their ability to support virus entry, replication, maturation and egress [1]. Virus entry depends on the expression of specific cellular receptors. In general, a range of proteins, carbohydrates and lipids can serve as virus receptors. The majority of enveloped viruses, i.e. viruses surrounded by a lipid bilayer derived from the host cell inner or outer membranes, achieve cellular entry by docking to specific membrane proteins that extend into the extracellular space. These highly diverse receptors usually react with viral fusion proteins called peplomers or spikes, which protrude from the viral surface. The viral core is released into the cytoplasm after fusion

\footnotetext{
* Corresponding author.
}

of the cellular membrane and the viral envelope [1]. Viral fusion proteins are usually expressed as precursor proteins into the endoplasmic reticulum, where they oligomerize and are cleaved by cellular proteases into receptor-binding and membrane fusion subunits, which remain bound to each other. Typically, they subsequently get transported to the cell surface or internal membrane systems [1].

Identification of viral receptors is crucial for understanding the host and tissue tropisms of a virus, which in turn shed light on the pathogenesis of viral diseases. Furthermore, variations in the receptor or its expression can contribute to differences in severity of disease. An understanding of viral entry might also allow development of substances that prevent viral binding to receptors or that freeze the entry process shortly thereafter. Despite considerable scientific interest, only a limited number of viral receptors have been identified so far [1]. 


\section{Coronaviruses}

The viral family Coronaviridae is a member of the order Nidovirales, which additionally contains the Arteriviridae and Roniviridae [2, 3]. The viruses of these families share certain genomic features and transcription strategies but differ in morphology. Their most prominent shared feature is that they all biosynthesize a nested set of subgenomic messenger RNAs (mRNAs) - a strategy not seen in any other viral group [2]. Human pathogens are found only among viruses of the family Coronaviridae, which contains the two genera Coronavirus and Torovirus [2].

Coronaviruses are large, enveloped, spherical viruses about $100-120 \mathrm{~nm}$ in diameter, which contain singlestranded RNA genomes with positive polarity. The coronaviral RNA genome is bound to nucleocapsid (N) proteins. Together, they form a flexible, helical ribonucleocapsid, which is contained in an icosahedral inner core made of matrix (M) proteins. The lipid envelope, which surrounds the inner core, is formed during viral budding from intracellular membranes [4-6]. Coronaviruses received their name from their overall shapes, which, due to the large $(20-40 \mathrm{~nm})$ petal-shaped spikes protruding from the envelope, resemble crowns (Latin: coronae). With lengths between 27 and $32 \mathrm{~kb}$, coronaviruses possess the largest genomes of all RNA viruses. The replication strategy of these viruses results in high-frequency recombination of their genomes. Coronaviruses infect a wide variety of species, including many mammals and birds. They cause both acute and chronic upper respiratory, gastrointestinal, hepatic and central nervous system (CNS) diseases [4-6].

\section{Coronaviral spike proteins and receptors}

The wide range of hosts infectable by coronaviruses is largely attributable to the variability of their spike proteins. Similarly, the virulence of coronavirus strains is also tightly associated with variations in these proteins [7-9]. Coronaviral spikes are type I membrane proteins which contain an N-terminal receptor-binding (S1) and a C-terminal membrane fusion (S2) domain [10]. The S2 domain contains amphipathic heptad repeats [10], which are predicted to engage in coiled-coil formation during cell-virus fusion. Based on models of cell fusion established with human immunodeficiency virus 1 (HIV-1) and influenza viruses, S1 binding to the receptor would induce exposure of a fusion peptide embedded in $\mathrm{S} 2$, which would then induce reorganization of the heptad repeats into coiled coils. Cellular membrane and viral envelope are thereby brought into close apposition [11-13]. Currently, two classes of fusion proteins are distinguished. Class I viral fusion proteins contain internal heptad repeat regions and an $\mathrm{N}$-terminal fusion peptide.
Class II proteins are heterodimers, lack these regions and possess internal fusion peptides [14]. Coronaviral spikes are similar to class I fusion proteins in that they are type I transmembrane proteins with heptad repeat regions synthesized in the endoplasmic reticulum and transported to the plasma membrane, but differ from class I fusion proteins in their lack of an N-terminal fusion peptide and the large size of their heptad repeat regions [15].

Three different genetic and serological groups (groups 1-3) of coronaviruses have been described. However, this classification is undergoing revision [16]. Until the discovery of SARS-CoV in 2003, only two coronaviruses were known to be pathogenic for humans. Human coronavirus 229E (HCoV-229E), a group 1 coronavirus, and HCoV-OC43, a group 2 coronavirus, usually cause mild upper respiratory infections ranging from self-resolving common colds to severe pneumonia in immunocompromised patients $[17,18]$. The cellular receptor for $\mathrm{HCoV}$ $229 \mathrm{E}$ was identified as aminopeptidase N (APN, CD13) $[19,20]$. Other group 1 coronaviruses that use this same zinc metalloprotease for cell entry include feline infectious peritonitis virus, porcine transmissible gastroenteritis virus (TGEV), porcine epidemic diarrhea virus and canine coronavirus [21-24]. Recently, another human coronarvirus, designated HCoV-BL63, was isolated from an infant suffering from bronchiolitis and conjunctivitis $[25,26]$. It remains to be seen whether this virus also utilizes APN as a cell-entry receptor. The receptor for $\mathrm{HCoV}$ OC43 remains elusive. However, the receptor for another group 2 coronavirus, murine hepatitis virus (MHV), has been identified as a member of the pleiotropic family of carcinoembryonic antigen-cell adhesion molecules (CEACAMs), which are members of the immunoglobulin superfamily [27-30]. Bovine coronaviruses, which also belong to group 2, seem to bind to 9-O-acetylated sialic acids [31]. No receptors for group 3 coronaviruses, which typically have avian hosts, have been identified so far.

\section{The SARS coronavirus and its receptor}

In 2003, a novel coronavirus was identified as the etiological agent of severe acute respiratory syndrome (SARS), which had emerged in Southeast Asia [32-35]. SARS was recognized for the first time in 2002 when human inhabitants of Guangdong Province, China, presented with a flu-like disease characterized by pyrexia, myalgia, dyspnea and lymphopenia [36]. Many cases developed an acute pulmonary syndrome, which resulted in pneumonia, progressive respiratory failure and death in about $10 \%$ of cases. Spread of the virus occurred via airborne droplets and close contact with patients [37]. The natural reservoir of SARS-CoV remains elusive, but ferrets and domestic cats have been suggested as candidates because they are susceptible to infection and can transmit 
the virus [38]. Chinese ferret badgers, raccoon dogs and Himalayan palm civets have also been suggested as reservoirs because they have been found infected with SARSCoV-like viruses [39].

Initial analyses suggested that SARS-CoV does not belong to any of the three established coronaviral groups [40-43]. However, new data suggest that the virus clusters phylogenetically with group 2 coronaviruses $[44,45]$. SARS-CoV possesses an RNA genome of about $30 \mathrm{~kb}$. This genome begins with a putative leader sequence followed by two overlapping open reading frames, which encompass almost half the genome. A-1 ribosomal frameshift produces a polyprotein, which encodes nonstructural proteins like proteases, helicases and viral polymerase. The remainder of the genome encodes, among others, the viral structural components, i.e. the spike (S), envelope (E), membrane (M) and nucleocapsid (N) proteins [32, 41, 42]. Analyses of the predicted amino acid sequence of SARS-CoV spike protein revealed a low (20-27\%) pairwise amino acid identity to the spikes of other coronaviruses $[42,43]$, suggesting that this novel virus might use a different receptor than those identified for other coronaviruses.

Within months of publication of the SARS-CoV genome, a receptor, angiotensin-converting enzyme 2 (ACE2), was identified [46]. The approach taken was straightforward. ACE2 was immunoprecipitated from lysates of cells susceptible to SARS-CoV infection using the SARS-CoV S1 domain. The precipitated protein was then identified using mass spectrometry [46]. ACE2 has been demonstrated to bind SARS-CoV S1 specifically and with a high affinity of $1.7 \mathrm{nM}$ [47]. Recombinant and cellularly expressed ACE2 supports the formation of large multinucleated cells with spike-protein-expressing cells, and ACE2 expression in cells that are usually not susceptible to SARS-CoV infection allows entry of live virus. Finally, antibodies to ACE2 block viral replication in Vero E6 cells [46].

ACE2 is a carboxy-metalloprotease that was independently discovered in 2000 by two groups. The enzyme is a type I transmembrane protein of 805 amino acids, which contains a single metalloprotease active site with an HEXXH zinc binding domain. It is only distantly related to APN, the receptor for group 1 coronaviruses [48, 49]. ACE2 transcripts were shown to be synthesized in human heart, kidney, testis [48], gastrointestinal tract and lungs [50]. Immunohistochemical examinations demonstrated high levels of ACE2 expression in the endothelium of intramyocardial and intrarenal vessels and in the renal tubular epithelium [48].

ACE2 appears to counter the physiological actions of the related ACE, which cleaves the inactive peptide angiotensin I to the highly potent vasoconstrictor angiotensin II. In fact, ACE2 has been shown to cleave angiotensin I to the metabolite angiotensin(1-9), which in turn is cleaved to angiotensin(1-7) [48, 51]. Angiotensin(1-7) has been identified as a vasodilator with antidiuretic effects. Recently, its receptor, the G-protein-coupled protooncogene Mas, has been identified [52]. ACE2 also cleaves des-argbradykinin, neurotensin and kinetensin [48]. The enzyme contains one catalytic domain that is $42 \%$ identical to each of the two respective domains of ACE. However, inhibitors of ACE like captopril or enalapril, which are used clinically to lower blood pressure, have no effect on the enzymatic activity of ACE2 [48, 49].

There is a considerable overlap of the tissue distribution of ACE2 with the distribution of SARS-CoV replication and the symptomatic manifestation of SARS [50]. For example, the primary site of SARS-CoV replication is the lungs [35], which have been shown to express ACE2 $[46,48,50,51]$. ACE2 is highly expressed in gastrointestinal tract and kidneys, tissues from which SARS$\mathrm{CoV}$ has been isolated [48, 50, 51]. However, ACE2 is strongly expressed in the human heart [48], but viral replication has not been detected in this organ. This discrepancy could be explained if SARS-CoV cell entry were dependent on cellular coreceptors, or other cellular factors, that are not well expressed in the heart. Alternatively, access of the virus to ACE2-expressing heart tissue may be limited.

Experiments imply that SARS-CoV cell fusion occurs at neutral $\mathrm{pH}$ and that no viral proteins other than the spike protein are required for the event [46, 54]. Curiously, the spike protein is not cleaved [46, 54], which is consistent with spike proteins of other group 1 coronaviruses [4] and in contrast to group 2 and 3 coronavirus spike proteins $[15,55,56]$ and to the fusion proteins of other viruses. The ACE2 binding site has been localized to a small region in the S1 domain. A SARS-CoV S1 fragment consisting of only 193 amino acids (residues 318-510) binds ACE2 even more efficiently than the full-length SARSCoV S1 domain [57, 58]. At least two amino acids (glutamic acid 452 and aspartic acid 454) of the $\mathrm{S}$ protein are crucial for ACE2 association. The receptor binding domain is distinct from those of MHV and $\mathrm{HCoV}-229 \mathrm{E}$, which is consistent with the use of distinct receptors by these viruses [57].

An enzymatically inactive ACE2 variant still binds SARS-CoV spike protein and facilitates entry, implying that the proteolytic activity of ACE2 plays no significant role in SARS-CoV cell entry [46]. This is not surprising, since cell entry of the group 1 coronavirus TGEV is also independent of the proteolytic activity of its receptor, APN. In fact, neither inhibition of APN's catalytic site nor mutation of the site itself blocks TGEV cell entry [59]. It remains unclear why these different coronaviruses utilize diverse zinc metalloproteases as receptors.

Preliminary results also suggest that binding of SARS$\mathrm{CoV}$ spike protein does not alter the enzymatic activity of ACE2 [J. H. Kuhn, unpublished]. It remains unclear whether spike protein binding leads to up- or downregu- 
lation of ACE2 expression, to downstream signaling or to cleavage of any SARS coronaviral protein.

To simplify studies of SARS-CoV, a system using simian immunodeficiency virus (SIV) or murine leukemia virus (MLV) expressing green fluorescent protein (GFP) and pseudotyped with a codon-optimized form of SARS$\mathrm{CoV}$ spike protein has been developed [60]. This system allows characterization of the interaction between ACE2 and SARS-CoV spike protein without using live SARS$\mathrm{CoV}$, obviating the requirement for stringent biosafety conditions. The system should facilitate the search for small-molecule inhibitors of receptor binding or entry and the testing of anti-sera to the SARS-CoV spike protein or its complex with ACE2. It may also be used to deliver target genes to ACE2-expressing cells.

Two therapeutic approaches have been shown effective in tissue culture. First, recombinant SARS-CoV spike protein or fragments thereof could be used as therapeutics, since they competitively inhibit binding of the virions to ACE2. The identification of a 193-amino-acid S1 fragment that binds to ACE2 [57] is a step in this direction. This fragment blocks cell entry of pseudotyped SIV at lower concentrations $(50 \%$ inhibitory concentration $\left(\mathrm{IC}_{50}\right)$ of $10 \mathrm{nM}$ under these experimental conditions) than the full-length $\mathrm{S} 1$ domain $\left(\mathrm{IC}_{50}\right.$ of $\left.50 \mathrm{nM}\right)$. It should be noted, though, that these studies were performed using cells expressing unphysiologically high levels of ACE2 [57] and may underestimate the potency of this reagent in vivo. Efforts are under way to characterize the structure of this S1 fragment and to increase its affinity [S. W. Wong, unpublished]. Second, soluble recombinant ACE2 (sACE2) may also be used as a decoy to scavenge SARS$\mathrm{CoV}$ in the bloodstream of infected patients [61]. ACE2 is most likely an essential regulator of blood pressure within local renin-angiotensin-aldosterone systems [52, 62], and also plays an important role in cardiovascular physiology [63, 64]. Thus, only catalytically inactive forms of sACE2 have potential as therapeutics for SARS, since only those forms would not interfere with regular physiological feedback systems. Such a mutated sACE2 can block infection of cells by an SIV pseudotype more potently than does the S1 fragment [60].

To date, there is no reliable animal model for SARS, although domestic cats, ferrets and monkeys have been proposed [32, 38]. Recently, murine ACE2 has been cloned and expressed. The molecule was determined to be $83 \%$ identical to its human counterpart [65]. Mice may be infectable with SARS-CoV, but their viral loads are low and they do not develop disease. Consistent with this observation, murine ACE2 binds to SARS-CoV S1 with low affinity [66]. However, robust SARS-CoV replication was observed after introducing human ACE2 into murine $3 \mathrm{~T} 3$ cells, indicating that the cell entry step is the primary bottleneck of virus replication in mice [66]. This suggests that mice transgenic for human ACE2 may be a useful animal model. Similar studies with ACE2 of other animals may cast light on the animal reservoir of the virus.

Several questions remain outstanding. First, do zinc metalloprotease receptors in general offer some advantages to allow coronavirus cell entry, or is the finding of several viruses (HCoV-229E, SARS-CoV) using diverse variants of these enzymes (APN, ACE2) a coincidence? Second, does ACE2 cleave SARS-CoV proteins on the virion surface, perhaps generating bioactive peptides that contribute to SARS pathogenesis? Third, is ACE2 the only cellular factor permitting SARS-CoV cell entry or are coreceptors involved? Fourth, does the inflammatory response to SARS-CoV lead to upregulation of ACE2 expression in lung tissue? If previous progress in SARS research is any indication, answers to these questions will be forthcoming shortly.

1 Young J. A. T. (2001) Virus entry and uncoating. In: Fundamental Virology, pp. 87-103, Knipe D. M. and Howley P. M. (eds), Lippincott Williams and Wilkins, Philadelphia

2 Enjuanes L., Spaan W., Snijder E. and Cavanagh D. (2000) Nidovirales. In: Virus Taxonomy, Seventh Report of the International Committee for the Taxonomy of Viruses, pp. 827-834, Regenmortel M. H. V., Fauquet C. M., Bishop D. H. L., Carsten E. B., Estes M. K., Lemon S. M. et al. (eds), Academic Press, New York

3 Mayo M. A. (2002) A summary of taxonomic changes recently approved by ICTV. Arch. Virol. 147: 1655-1663

4 Lai M. M. C. and Holmes K. V. (2001) Coronaviridae: the viruses and their replication. In: Fundamental Virology, pp. 641-663, Knipe D. M. and Howley P. M. (eds), Lippincott Williams and Wilkins, Philadelphia

5 Lavi E., Weiss S. R. and Hingley S. T. (2001) The Nidoviruses (Coronaviruses and Arteriviruses), Kluwer Academic/Plenum Publishers, New York

6 Siddell S. (1995) The Coronaviridae, Plenum Press, New York

7 Kuo L., Godeke G. J., Raamsman M. J., Masters P. S. and Rottier P. J. (2000) Retargeting of coronavirus by substitution of the spike glycoprotein ectodomain: crossing the host cell species barrier. J. Virol. 74: 1393-1406

8 Phillips J. J., Chua M. M., Lavi E. and Weiss S. R. (1999) Pathogenesis of chimeric MHV4/MHV-A59 recombinant viruses: the murine coronavirus spike protein is a major determinant of neurovirulence. J. Virol. 73: 7752-7760

9 Sanchez C. M., Izeta A., Sanchez-Morgado J. M., Alonso S., Sola I., Balasch M. et al. (1999) Targeted recombination demonstrates that the spike gene of transmissible gastroenteritis coronavirus is a determinant of its enteric tropism and virulence. J. Virol. 73: 7607-7618

10 Gallagher T. M. (2001) Murine coronavirus spike glycoprotein. Receptor binding and membrane fusion activities. Adv. Exp. Med. Biol. 494: 183-192

11 Colman P. M. and Lawrence M. C. (2003) The structural biology of type I viral membrane fusion. Nat. Rev. Mol. Cell Biol. 4: 309-319

12 Singh M., Berger B. and Kim P. S. (1999) LearnCoil-VMF: computational evidence for coiled-coil-like motifs in many viral membrane-fusion proteins. J. Mol. Biol. 290: 1031-1041

13 Skehel J. J. and Wiley D. C. (1998) Coiled coils in both intracellular vesicle and viral membrane fusion. Cell 95: 871-874

14 Lescar J., Roussel A., Wien M. W., Navaza J., Fuller S. D., Wengler G. et al. (2001) The Fusion glycoprotein shell of Semliki 
Forest virus: an icosahedral assembly primed for fusogenic activation at endosomal $\mathrm{pH}$. Cell 105: $137-148$

15 Bosch B. J., van der Zee R., de Haan C. A. and Rottier P. J. (2003) The coronavirus spike protein is a class I virus fusion protein: structural and functional characterization of the fusion core complex. J. Virol. 77: 8801-8811

16 Gonzalez J. M., Gomez-Puertas P., Cavanagh D., Gorbalenya A. E. and Enjuanes L. (2003) A comparative sequence analysis to revise the current taxonomy of the family Coronaviridae. Arch. Virol. 148: 2207-2235

17 Denison M. R. (1999) The common cold. Rhinoviruses and coronaviruses. In: Viral Infections of the Respiratory Tract, pp. 253-280, Dolin R. and Wright F. P. (eds), Marcel Dekker, New York

18 Pene F., Merlat A., Vabret A., Rozenberg F., Buzyn A., Dreyfus F. et al. (2003) Coronavirus 229E-related pneumonia in immunocompromised patients. Clin. Infect. Dis. 37: 929-932

19 Bonavia A., Zelus B. D., Wentworth D. E., Talbot P. J. and Holmes K. V. (2003) Identification of a receptor-binding domain of the spike glycoprotein of human coronavirus $\mathrm{HCoV}$ 229E. J. Virol. 77: 2530-2538

20 Yeager C. L., Ashmun R. A., Williams R. K., Cardellichio C. B., Shapiro L. H., Look A. T. et al. (1992) Human aminopeptidase $\mathrm{N}$ is a receptor for human coronavirus 229E. Nature 357: 420422

21 Benbacer L., Kut E., Besnardeau L., Laude H. and Delmas B. (1997) Interspecies aminopeptidase-N chimeras reveal speciesspecific receptor recognition by canine coronavirus, feline infectious peritonitis virus, and transmissible gastroenteritis virus. J. Virol. 71: 734-737

22 Delmas B., Gelfi J., L'Haridon R., Vogel L. K., Sjostrom H., Noren O. et al. (1992) Aminopeptidase N is a major receptor for the entero-pathogenic coronavirus TGEV. Nature 357: 417420

23 Oh J. S., Song D. S. and Park B. K. (2003) Identification of a putative cellular receptor $150 \mathrm{kDa}$ polypeptide for porcine epidemic diarrhea virus in porcine enterocytes. J. Vet. Sci. 4: 269- 275

24 Tresnan D. B. and Holmes K. V. (1998) Feline aminopeptidase $\mathrm{N}$ is a receptor for all group I coronaviruses. Adv. Exp. Med. Biol. 440: 69-75

25 Fouchier R. A. M., Hartwig H. G., Bestebroer T. M., Niemeyer B., de Jong J. C., Simon J. H. et al. (2004) A previously undescribed coronavirus associated with respiratory disease in humans. Proc. Natl. Acad. Sci. USA 101: 6212-6216

26 van der Hoek L., Pyrc K., Jebbink M. F., Vermeulen-Oost W., Berkhout R. J. M., Wolthers K. C. et al. (2004) Identification of a new human coronavirus. Nat. Med. 10: 368-373

27 Dveksler G. S., Dieffenbach C. W., Cardellichio C. B., McCuaig K., Pensiero M. N., Jiang G. S. et al. (1993) Several members of the mouse carcinoembryonic antigen-related glycoprotein family are functional receptors for the coronavirus mouse hepatitis virus-A59. J. Virol. 67: 1-8

28 Dveksler G. S., Pensiero M. N., Cardellichio C. B., Williams R. K., Jiang G. S., Holmes K. V. et al. (1991) Cloning of the mouse hepatitis virus (MHV) receptor: expression in human and hamster cell lines confers susceptibility to MHV. J. Virol. 65: 68816891

29 Kubo H., Yamada Y. K. and Taguchi F. (1994) Localization of neutralizing epitopes and the receptor-binding site within the amino-terminal 330 amino acids of the murine coronavirus spike protein. J. Virol. 68: 5403-5410

30 Williams R. K., Jiang G. S. and Holmes K. V. (1991) Receptor for mouse hepatitis virus is a member of the carcinoembryonic antigen family of glycoproteins. Proc. Natl. Acad. Sci. USA 88: $5533-5536$

31 Holmes K. V. and Dveksler G. S. (1994) Specificity of coronavirus/receptor interaction. In: Cell Receptors for Animal Viruses, pp. 403-443, Wimmer E. (ed.), Cold Spring Harbor Press, Cold Spring Harbor
32 Drosten C., Gunther S., Preiser W., van der Werf S., Brodt H. R., Becker S. et al. (2003) Identification of a novel coronavirus in patients with severe acute respiratory syndrome. N. Engl. J. Med. 348: 1967-1976

33 Fouchier R. A., Kuiken T., Schutten M., van Amerongen G., van Doornum G. J., van den Hoogen B. G. et al. (2003) Aetiology: Koch's postulates fulfilled for SARS virus. Nature 423: 240

34 Ksiazek T. G., Erdman D., Goldsmith C. S., Zaki S. R., Peret T., Emery S. et al. (2003) A novel coronavirus associated with severe acute respiratory syndrome. N. Engl. J. Med. 348: 1953- 1966

35 Kuiken T., Fouchier R. A., Schutten M., Rimmelzwaan G. F., van Amerongen G., van Riel D. et al. (2003) Newly discovered coronavirus as the primary cause of severe acute respiratory syndrome. Lancet 362: 263-270

36 Peiris J. S., Chu C. M., Cheng V. C., Chan K. S., Hung I. F., Poon L. L. et al. (2003) Clinical progression and viral load in a community outbreak of coronavirus-associated SARS pneumonia: a prospective study. Lancet 361: 1767-1772

37 Stadler K., Masignani V., Eickmann M., Becker S., Abrignani S., Klenk H. D. et al. (2003) SARS - beginning to understand a new virus. Nat. Rev. Microbiol. 1: 209-218

38 Martina B. E., Haagmans B. L., Kuiken T., Fouchier R. A., Rimmelzwaan G. F., Van Amerongen G. et al. (2003) Virology: SARS virus infection of cats and ferrets. Nature 425: 915

39 Guan Y., Zheng B. J., He Y. Q., Liu X. L., Zhuang Z. X., Cheung C. L. et al. (2003) Isolation and characterization of viruses related to the SARS coronavirus from animals in southern China. Science 302: 276-278

40 Eickmann M., Becker S., Klenk H. D., Doerr H. W., Stadler K., Censini S. et al. (2003) Phylogeny of the SARS coronavirus. Science 302: 1504-1505

41 Marra M. A., Jones S. J., Astell C. R., Holt R. A., Brooks-Wilson A., Butterfield Y. S. et al. (2003) The Genome sequence of the SARS-associated coronavirus. Science 300: 1399-1404

42 Rota P. A., Oberste M. S., Monroe S. S., Nix W. A., Campagnoli R., Icenogle J. P. et al. (2003) Characterization of a novel coronavirus associated with severe acute respiratory syndrome. Science 300: 1394-1399

43 Spiga O., Bernini A., Ciutti A., Chiellini S., Menciassi N., Finetti F. et al. (2003) Molecular modelling of S1 and S2 subunits of SARS coronavirus spike glycoprotein. Biochem. Biophys. Res. Commun. 310: 78-83

44 Gibbs A. J., Gibbs M. J. and Armstrong J. S. (2004) The phylogeny of SARS coronavirus. Arch. Virol., in press

45 Gorbalenya A. E., Snijder E. J. and Spaan W. J. M. (2004) Severe acute respiratory coronavirus phylogeny: toward consenus. J. Virol. 78: 7863-7866

46 Li W., Moore M. J., Vasilieva N., Sui J., Wong S. K., Berne M. A. et al. (2003) Angiotensin-converting enzyme 2 is a functional receptor for the SARS coronavirus. Nature 426: $450-454$

47 Sui J., Li W., Murakami A., Tamin A., Matthews L. J., Wong S. K. et al. (2004) Potent neutralization of severe acute respiratory syndrome (SARS) coronavirus infection by a human mAb to SI protein that blocks receptor association. Proc. Natl. Acad. Sci. USA, in press

48 Donoghue M., Hsieh F., Baronas E., Godbout K., Gosselin M., Stagliano N. et al. (2000) A novel angiotensin-converting enzyme-related carboxypeptidase (ACE2) converts angiotensin I to angiotensin 1-9. Circ. Res. 87: E1-9

49 Tipnis S. R., Hooper N. M., Hyde R., Karran E., Christie G. and Turner A. J. (2000) A human homolog of angiotensin-converting enzyme. Cloning and functional expression as a captoprilinsensitive carboxypeptidase. J. Biol. Chem. 275: $33238-$ 33243

50 Hamming I., Timens W., Bulthuis M. L. C., Lely A. T., Navis G. J. and van Goor H. (2004) Tissue distribution of ACE2 protein, the functional receptor for SARS coronavirus. A first step in understanding SARS pathogenesis. J. Pathol. 203: 631-637 
51 Harmer D., Gilbert M., Borman R. and Clark K. L. (2002) Quantitative mRNA expression profiling of ACE 2, a novel homologue of angiotensin converting enzyme. FEBS Lett. 532: $107-110$

52 Schmaier A. H. (2003) The kallikrein-kinin and the renin-angiotensin systems have a multilayered interaction. Am. J. Physiol. Regul. Integr. Comp. Physiol. 285: R1-13

53 Santos R. A., Simoes e Silva A. C., Maric C., Silva D. M., Machado R. P., de Buhr I. et al. (2003) Angiotensin-(1-7) is an endogenous ligand for the $G$ protein-coupled receptor Mas. Proc. Natl. Acad. Sci. USA 100: $8258-8263$

54 Xiao X., Chakraborti S., Dimitrov A. S., Gramatikoff K. and Dimitrov D. S. (2003) The SARS-CoV S glycoprotein: expression and functional characterization. Biochem. Biophys. Res. Commun. 312: 1159-1164

55 Jackwood M. W., Hilt D. A., Callison S. A., Lee C. W., Plaza H. and Wade E. (2001) Spike glycoprotein cleavage recognition site analysis of infectious bronchitis virus. Avian Dis. 45: $366-$ 372

56 Sturman L. S. and Holmes K. V. (1984) Proteolytic cleavage of peplomeric glycoprotein E2 of MHV yields two 90K subunits and activates cell fusion. Adv. Exp. Med. Biol. 173: 25-35

57 Wong S. K., Li W., Moore M. J., Choe H. and Farzan M. (2004) A 193-amino-acid fragment of the SARS coronavirus S protein efficiently binds angiotensin-converting enzyme 2. J. Biol. Chem. 279: 3197-3201

58 Babcock G. J., Esshaki D. J., Thomas Jr. W. D. and Ambrosino D. M. (2004) Amino acids 270 to 510 of the severe acute respiratory syndrome coronavirus spike protein are required for interaction with receptor. J. Virol. 78: 4552-4560

59 Delmas B., Gelfi J., Kut E., Sjostrom H., Noren O. and Laude H. (1994) Determinants essential for the transmissible gas- troenteritis virus-receptor interaction reside within a domain of aminopeptidase-N that is distinct from the enzymatic site. J. Virol. 68: 5216-5224

60 Moore M. J., Dorfman T., Li W., Wong S. K., Li Y., Kuhn J. H. et al. (2004) Metroviruses pseudotyped with the severe acute respiratory syndrome coronavirus spike protein efficiently infect cells expressing angiotensin - converting enzyme 2, J. Virol. 78: in press

61 Hofman H., Geier M., Marzi A., Krumbiegel M., Peipp M., Fey G. H. et al. (2004) Susceptibility of SARS coronavirus S protein-driven infection correlates with expression of angiotensinconverting enzyme 2 and infection can be blocked by soluble receptor. Biochem. Biophys. Res. Commun. 319: 1216-1221

62 Yagil Y. and Yagil C. (2003) Hypothesis: ACE2 modulates blood pressure in the mammalian organism. Hypertension 41: $871-873$

63 Crackower M. A., Sarao R., Oudit G. Y., Yagil C., Kozieradzki I., Scanga S. E. et al. (2002) Angiotensin-converting enzyme 2 is an essential regulator of heart function. Nature 417: 822 828

64 Oudit G. Y., Crackower M. A., Backx P. H. and Penninger J. M. (2003) The role of ACE2 in cardiovascular physiology. Trends Cardiovasc. Med. 13: 93-101

65 Komatsu T., Suzuki Y., Imai J., Sugano S., Hida M., Tanigami A. et al. (2002) Molecular cloning, mRNA expression and chromosomal localization of mouse angiotensin-converting enzyme-related carboxypeptidase (mACE2). DNA Seq. 13: $217-220$

66 Li W., Greenough T. C., Moore M. J., Vasilieva N., Somasundaran M., Sullivan J. et al. (2004) Efficient replication of SARS coronavirus in mouse cells is limited by murine angiotensinconverting enzyme 2. J. Virol., in press 